\title{
REDIMAT
}

Journal of Research in Mathematics Education

Instructions for authors, subscriptions and further details:

http://redimat.hipatiapress.com

\section{Inventing the Mathematician. Gender, Race, and Our Cultural Understanding of Mathematics.}

Elena Duque Sánchez 1

1) Universitat de Girona, España.

Date of publication: Junio $24^{\text {th }}, 2016$

Edition period: Junio 2016-Octubre 2016

To cite this article: Duque, E. (2016). Inventing the mathematician. Gender, race and our cultural understanding of Mathematics. REDIMAT, 5(2), 205207. doi: $10.4471 /$ redimat.2016.2138

To link this article: http://dx.doi.org/10.4471/redimat.2016.2138

\section{PLEASE SCROLL DOWN FOR ARTICLE}

The terms and conditions of use are related to the Open Journal System and to Creative Commons Attribution License (CC-BY). 
REDIMAT, Vol. 5 No. 2 June $24^{\text {th }} 2016$ pp. 205-207

\section{Review}

Hottinger, S.N. (2016). Inventing the Mathematician. Gender, Race, and Our Cultural Understanding of Mathematics. State University of New York: SUNY Press.

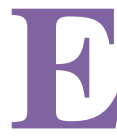

1 libro titulado «Inventing the Mathematician» es una intersante reflexión sobre el papel que ha jugado la mujer en las matemáticas, a lo largo de la historia. A pesar de que en una época tan ancestral como el siglo cuarto antes de Cristo ya tenemos evidencias de que existió una mujer en Alejandría llamada Hipatia, que realizó aportaciones significativas a las matemáticas, lo cierto es que una revisión de la historia de las matemáticas nos deja más bien un resultado pobre en cuanto al reconocimiento de la labor de las mujeres en este ámbito del conocimiento. La autora de este libro, al inicio del primer capítulo, incluye una cita de Valerie Walkerdine donde afirma que tan solo hay dos mujeres en la historia de las matemáticas: Sofia Kovalevskaya y Emmy Noether. Aunque lo cierto es que existen algunas mujeres más que forman parte de ese club de féminas que han dejado contribuciones importantes en la matemática, también hay que reconocer que el rol de la mujer en el mundo de las matemáticas ha sido (y es) muy reducido. A pesar de investigaciones como las de Elisabeth Fennema que en 1976 ya publicó junto con Sherman un estudio sobre las actitudes de las matemáticas entre hombres y mujeres, demostrando que la variable género no es explicativa para nada de las diferencias entre hombres y mujeres hacia la matemática, aún hoy seguimos viendo que existe una profunda discriminación hacia las mujeres en este ámbito.

Quizás sea un problema de origen social, tal y como explican sociólogos y sociólogas con conceptos como el de socialización. Lo cierto es que aún hoy vemos a pocas mujeres en las facultades de ingeniería, a pesar de que los resultados escolares de las chicas en primeria y en secundaria acostumbran a ser mejores que los de sus compañeros a esas edades. Sin 
embargo, cuando pasamos al ámbito universitario, la desigualdad se hace manifiesta simplemente entrando en un aula de primero de prácticamente cualquier ingeniería.

La autora de este libro afirma que existe una construcción discursiva de la "subjetividad de género." Es decir, que plantea que el ser mujer o ser hombre es en realidad una consecuencia de un discurso narrativo que existe en torno a dichas realidades. A partir de cuatro enfoques diferentes, justifica que en realidad la matemática es una construcción cultural. La matemática, tal y como la conocemos, es heredera de una forma muy concreta, que varios autores han definido como western mathematics, y que hunde sus raíces en la Grecia clásica. Pero incluso trabajos más modernos, como los de Newton o Ramanujan, de los que la autora habla profusamente, muestran cómo matemáticos procedentes de diferentes orígenes culturales acaban produciendo unas matemáticas con un discurso similar. La autora recurre a argumentos como los de Paul Ernets cuando define lo que él considera como mathematica subjectivity, y que está profundamente a pesar de presentarse como algo "abstracto", "racional", "frío", lo cierto es que está profundamente marcado en el sentido cultural, por una serie de valores y discursos que fácilmente se pueden definir como "masculinos", "occidentales", "blancos", etc.

Por otro lado, usando la metáfora del "retrato" (que es un tipo "occidental" de arte), la autora explora cómo los matemáticos han definido ellos mismos su disciplina. A través de la Historia de la Matemática de Burton, principalmente, aunque no de manera exclusiva, Hottinger analiza los diferentes retratos de matemáticos que aparecen en las obras de referencia de que disponemos. Por ejemplo, en dicho libro de referencia sobre la historia de la matemática, Burton presenta 45 retratos de matemáticos; solo dos de ellos corresponden con mujeres, lo cual realmente llama mucho la atención.

Finalmente, la autora utiliza el enfoque de la etnomatemática com recurso para hacer una revisión critica de todo lo dicho. Este enfoque históricamente aparece como un planteamiento alternativo hacia la Western Mathematics. A lo largo de las últimas páginas de su libro, Hottinger justifica que un enfoque cultural o, por lo menos, sensible con los aspectos culturales, puede abrir la posibilidad a repensar el papel de la mujer en un ámbito del saber que debería ser de todos y todas, e incluir las aportaciones 
genuinas sin importar de dónde vienen. Este libro es una buena apuesta para ello, y ofrece una visión realmente sugerente para hacerlo.

Elena Duque Sánchez, Universitat de Girona, España

Elena.duque@udg.edu 